\title{
LIDERANÇA TECNOLÓGICA INTERMEDIÁRIA E DESENVOLVIMENTO DE COMPETÊNCIAS TECNOLÓGICAS: ESTUDO DE CASO EM UMA SUBSIDIÁRIA DO SETOR AUTOMOTIVO BRASILEIRO
}

\author{
INTERMEDIATE TECHNOLOGICAL LEADERSHIP AND \\ DEVELOPMENT OF TECHNOLOGICAL COMPETENCES: A CASE \\ STUDY IN A BRAZILIAN AUTOMOTIVE SUBSIDIARY
}

\author{
Raoni Barros Bagno'; Lin Chih Cheng ${ }^{2}$; \\ ${ }^{1}$ Fiat Powertrain Technologies - FPT - Belo Horizonte - Brasil rbagno@uai.com.br \\ ${ }^{2}$ Universidade Federal de Minas Gerais - UFMG - Belo Horizonte - Brasil lincheng@ ufmg.br
}

\begin{abstract}
Resumo
O objetivo do presente artigo é mostrar como vem sendo feita a construção de competências tecnológicas em inovação de produto em uma subsidiária do setor automotivo brasileiro norteada pelo conceito de 'Liderança Tecnológica Intermediária'(LTI) como propósito empresarial. Após uma abordagem histórica focada na evolução tecnológica da indústria automobilística no Brasil, uma breve análise da literatura estabelece uma relação direta entre o papel desempenhado pelas subsidiárias brasileiras de organizações globais e a busca de conhecimentos gerenciais $e$ tecnológicos, associada à estrutura organizacional necessária para sua plena efetivação. A discussão é ilustrada pela análise da construção de competências aplicada ao desenvolvimento de um sistema 'robotizado' de transmissão veicular. Esta análise é realizada por meio de imersão no ambiente organizacional, coleta de informações de documentos internos e entrevistas não-diretivas com lideranças e engenheiros diretamente envolvidos no processo. Por intermédio do caso apresentado são identificados pontos fundamentais para a construção de competências como a necessidade de implementação de mecanismos de aprendizado organizacional, desenvolvimento de pesquisa tecnológica e estabelecimento prévio de estruturas pessoal e física. Dentre os principais benefícios de uma postura ativa das subsidiárias locais na construção destas novas competências, destacam-se o desenvolvimento de indústrias envolvidas na cadeia produtiva e o incremento em qualidade dos empregos gerados no setor.
\end{abstract}

Palavras-chave: Competências tecnológicas, desenvolvimento de produtos, inovação tecnológica, indústria automobilística.

\section{Introdução}

Desde a instalação das primeiras montadoras de automóveis no Brasil na primeira metade do século passado, a indústria automobilística brasileira vem passando por um importante processo de evolução de suas competências tecnológicas. Em seu primeiro nível, este setor é dominado por 
subsidiárias de empresas estrangeiras, que, partindo da simples montagem de componentes importados, possui hoje exemplos de destaque no desenvolvimento de produtos em nível mundial.

A presente década representa um momento importante nesta evolução. O estágio de desenvolvimento das principais subsidiárias brasileiras do setor automobilístico, associado a características sócio-econômicas do mercado local e fenômenos organizacionais de ordem global, promovem a configuração de um quadro no qual a construção de competências tecnológicas nas subsidiárias brasileiras do setor aparece como propósito organizacional de destaque. O termo Liderança Tecnológica Intermediária ${ }^{1}$ visa sintetizar este propósito e o sucesso na sua busca pode potencialmente atrair benefícios importantes para a consolidação do país como base de inovações e novas tecnologias. Outros resultados seriam o desenvolvimento de empresas ligadas ao setor e a geração de empregos mais nobres em comparação com aqueles oriundos das estratégias de industrialização praticadas ao longo da história.

Embora realidades semelhantes possam também estar representadas em outros setores industriais, conforme importantes trabalhos citados ao longo do texto, o setor escolhido para este trabalho possui características peculiares devido, entre outros fatores, à extensão e diversidade da cadeia produtiva envolvida, velocidade em que artefatos tecnológicos vêm sendo agregados ao produto final e relevantes especificidades locais de mercado. Neste contexto, o tópico 2 realiza uma breve abordagem histórica do desenvolvimento do setor automobilístico no Brasil. Em seqüência, o tópico 3 estabelece uma base teórica para o desenvolvimento de competências tecnológicas locais, detalhando ao seu final o conceito de Liderança Tecnológica Intermediária. O tópico 4 precede o caso prático fornecendo informações sobre a estratégia metodológica e justificando a escolha do caso pesquisado no tópico 5, que apresenta uma análise da construção de competências em torno do desenvolvimento e aplicação de um sistema 'robotizado' de transmissão veicular. As conclusões do estudo são finalmente explicitadas no tópico 6.

\section{Perspectiva histórica da evolução das competências tecnológicas na indústria automobilística brasileira}

O setor automobilístico brasileiro foi inaugurado com a instalação da Ford, em 1919, seguida pela General Motors em 1925. Os trabalhos iniciais destas subsidiárias ocorreram na montagem de veículos no sistema CKD (Completely Knocked Down) e na prestação de serviços de manutenção (FLEURY \& FLEURY, 1997). Até a segunda grande guerra, o Brasil não contava com um parque automotivo completo, havendo somente a montagem de veículos no país, sem, contudo,

\footnotetext{
${ }^{1}$ Liderança Tecnológica Intermediária, ou LTI, é um termo que visa representar o propósito organizacional de construção de competências tecnológicas complementares em subsidiárias de organizações globais. O termo é aplicado à indústria automobilística e será detalhado mais adiante.
} 
a fabricação de peças. Após este período, o governo manifestou especial interesse pelo setor automotivo, principalmente pela capacidade desta indústria em estimular o desenvolvimento de indústrias complementares (AEA, 2005).

Até 1990, as indústrias do setor operaram num contexto econômico confortável, protegido e subsidiado (FLEURY \& FLEURY, 1997). A década de 90 abriu então um novo cenário para o setor automotivo no Brasil. Neste período ocorreram intensas mudanças caracterizadas pela abertura do mercado às importações de veículos e autopeças; consolidação das estratégias de modernização das linhas de produtos; reestruturação do setor de autopeças após inúmeras fusões e aquisições; investimentos de novas montadoras, ou de montadoras já instaladas com novas plantas ou remodelamentos de antigas plantas (DIAS, 2003). Ao final dos anos 90, o setor possuía um perfil bastante diferente, com fábricas mais modernas e competitivas. O mesmo se verificava para o setor de autopeças. Chegando-se aos dias atuais, a expansão e modernização permanecem em andamento, abrangendo também fornecedores de segundo e terceiro níveis. Encontra-se hoje em destaque a importância da capacitação tecnológica local na indústria automobilística brasileira em termos de engenharia de produto e projeto (AEA, 2005).

Fleury e Fleury (2000) apontam que muitos aspectos da geração de empregos na indústria automotiva foram deixados à margem, principalmente aqueles ligados ao potencial de geração e consolidação de competências de desenvolvimento tecnológico através de investimento externo. No período de 1956 a 1961, a implantação das subsidiárias das grandes montadoras de automóveis foi o símbolo de uma tática de industrialização acelerada, da qual esperava-se a vinda de conhecimentos gerenciais e tecnológicos (FLEURY \& FLEURY, 1997). Baseados em estudos conduzidos pela FINEP, os autores afirmam que a função tecnológica não ocupava lugar prioritário nas empresas do Brasil, dando lugar ao marketing e ao controle financeiro. Já na década de 1980 foi constatada uma evolução no padrão de capacitação tecnológica, buscando a produção local de projetos licenciados por empresas estrangeiras. Ainda segundo os mesmos autores, um segundo estágio percorrido por algumas empresas foi a realização do detalhamento local dos projetos básicos de produtos enviados do exterior e um terceiro estágio foi o da capacitação local para o desenvolvimento de projetos básicos. Fleury e Fleury (1997) colocam, contudo, que cada fase de evolução contava com um número cada vez mais restrito de empresas. Numa perspectiva histórica, os autores consideram o processo de capacitação tecnológica no Brasil disperso e volátil.

Em última análise, considera-se positivo o momento da engenharia automotiva brasileira. No caso da General Motors do Brasil a engenharia brasileira teve seu início na adaptação de modelos estrangeiros chegando à condição de desenvolvimento de um veículo completo. Hoje a subsidiária brasileira é um dos 5 centros mundiais de desenvolvimento de engenharia do grupo, cabendo a ela o desenvolvimento de um novo modelo fora-de-estrada a diesel para o mercado 
Europeu. A habilidade desenvolvida no país tem sido ponto fundamental de decisões como a que levou a Fiat a construir um centro completo de desenvolvimento de produtos em sua subsidiária brasileira, o único fora da Itália. Existe previsão por parte das subsidiárias locais da Fiat e da GM de aumento do fornecimento de serviços prestados às suas matrizes e outras filiais. Ford e Volkswagen, por sua vez, têm seus funcionários cada vez mais envolvidos em projetos internacionais, sendo que o mesmo ocorre com os fornecedores de autopeças. Uma importante mudança está no caráter deste envolvimento, uma vez que em grande parte das experiências recentes, o fluxo da transferência de conhecimento e experiência tem sido invertido (BAGNO, 2007).

\section{Inovação e desenvolvimento de competências tecnológicas: a evolução dos propósitos organizacionais das subsidiárias do setor}

\subsection{Descentralização tecnológica e desenvolvimento de competências locais}

O desenvolvimento de competências de P\&D é atribuído a uma subsidiária conforme seu nível de autonomia no grupo industrial no qual se insere. Conforme observado por Fleury (1999), a trajetória ou evolução de cada subsidiária vem sendo definida em função de fatores locais, sendo considerada bem sucedida quando: desenvolve estratégias competitivas locais, estabelece estruturas organizacionais complexas, desenvolve produtos para o mercado local e elabora sistemas de gestão próprios. Observa-se também que os governos locais estão preocupados em atrair os investimentos estrangeiros através da criação de uma infra-estrutura local que potencialize a competitividade das subsidiárias frente ao cenário global.

Fleury (1999) identifica três diferentes tipos de subsidiárias no Brasil: o tipo I é a subsidiária que atua como braço operacional da matriz, o tipo III é a subsidiária que vem como centro de competências, garantindo autonomia no mercado local conforme a competência tecnológica e o tipo II permanece em uma fase intermediária aos tipos anteriores como uma unidade relativamente autônoma. Assim, observa-se que passa a haver uma diferenciação quanto ao gerenciamento do desenvolvimento de produtos dependendo da estratégia da empresa transnacional e do papel que ela estabelece para as subsidiárias. Os tipos de competência tecnológica são divididos hierarquicamente em: competências técnica e gerencial para operação de tecnologias existentes; Competências em desenho, engenharia, gestão e P\&D objetivando aprimoramento organizacional, de produtos e de processos; competências em P\&D e engenharia básica/gestão de projetos para copiar, implementar e desenvolver tecnologias existentes e; competências em P\&D e engenharia para desenvolver e implementar novas tecnologias (FIGUEIREDO, 2004). 
Várias são as evidências da crescente localização das atividades de desenvolvimento de produtos e tecnologia no Brasil. Os motivos que levam à internacionalização da P\&D vão desde apoio à produção local até o suporte aos sistemas de inovação locais. Neste aspecto, o contato com novos conhecimentos e tecnologias, flexibilidade e agilidade para adaptação de produtos, menores custos de desenvolvimento, incentivos fiscais e exigências para atuação local são alguns dos principais pontos envolvidos (GALINA, 2003).

\subsection{Níveis de competências tecnológicas das subsidiárias brasileiras da indústria automobilística}

Pode-se afirmar que o contexto de inovação tecnológica em economias industrializadas se diferencia daquele observado em países emergentes principalmente por ocorrer dentro de estruturas organizacionais mais maduras e por seguir a seqüência padrão: pesquisa-desenvolvimentoprodução. Figueiredo (2003) acrescenta que as empresas de países de tecnologia de fronteira já dispõem de competência tecnológica inovadora.

Nelson e Winter (1977) atestam que a estrutura institucional adequada para a inovação depende diretamente das tecnologias envolvidas, natureza da demanda por produtos e serviços e características das organizações da cadeia de fornecimento. Uma teoria de inovação necessitaria então ser suficientemente abrangente para relacionar corretamente o progresso tecnológico do setor com a estrutura institucional envolvida. Tigre (2006) coloca a necessidade de mudança das formas organizacionais para que a incorporação das oportunidades de inovação ocorra com sucesso. Tal mudança incorporaria diversas dimensões como alterações nos processos de negócios, mudanças nas cadeias hierárquicas de comando, formas de acesso à informações e reformulação de rotinas e estruturas de poder.

No contexto de economias emergentes, empresas normalmente iniciam seu negócio a partir da tecnologia adquirida de outras empresas em outros países, não dispondo, inicialmente, das capacidades tecnológicas básicas (FIGUEIREDO, 2004). Alguns autores observam que a acumulação tecnológica envolve uma seqüência evolutiva e cumulativa composta por etapas. No entanto, empresas que operam em economias emergentes parecem seguir uma trajetória distinta daquelas de países industrializados, invertendo a seqüência pesquisa-desenvolvimento-produção praticada por estas últimas (FIGUEIREDO, 2004). Figueiredo (2003) sugere que as competências tecnológicas de uma organização evoluam em níveis discretos. Analisando o caso das subsidiárias nacionais da indústria automobilística, Bagno (2007) sugere as seguintes etapas de evolução, ilustradas pela Figura 1: 
- $\quad$ Suporte à produção. $\mathrm{O}$ pólo desenvolvedor externo desenvolve o produto totalmente. $\mathrm{O}$ grupo local atua somente na fase de produção;

- Engenharia de Ligação. A função local serve de ligação com a matriz com relação aos problemas na produção e no campo. O produto ainda é desenvolvido no pólo externo, porém, validado localmente antes da produção.

- Engenharia de Aplicação. Ou engenharia de 'tropicalização'. Tem a missão de adaptar o produto já desenvolvido no pólo externo ao mercado local focando-se em diferenças de uso, questões climáticas, padrões locais, etc. Existe modificação de desenhos de produto localmente.

- Engenharia de Desenvolvimento. É responsável pelo desenvolvimento do produto segundo suas fases. Tais fases ocorrem majoritariamente na subsidiária local com maior ou menor interferência da matriz.

- Centro de competência em desenvolvimento de tecnologia e do produto. Atua no desenvolvimento do produto desde a fase de seleção e operacionalização das novas tecnologias a serem aplicadas. Possui autonomia na elaboração de conceitos dos novos produtos para o mercado local.

Figura 1 - Trajetória das competências tecnológicas de produto na indústria automobilística.

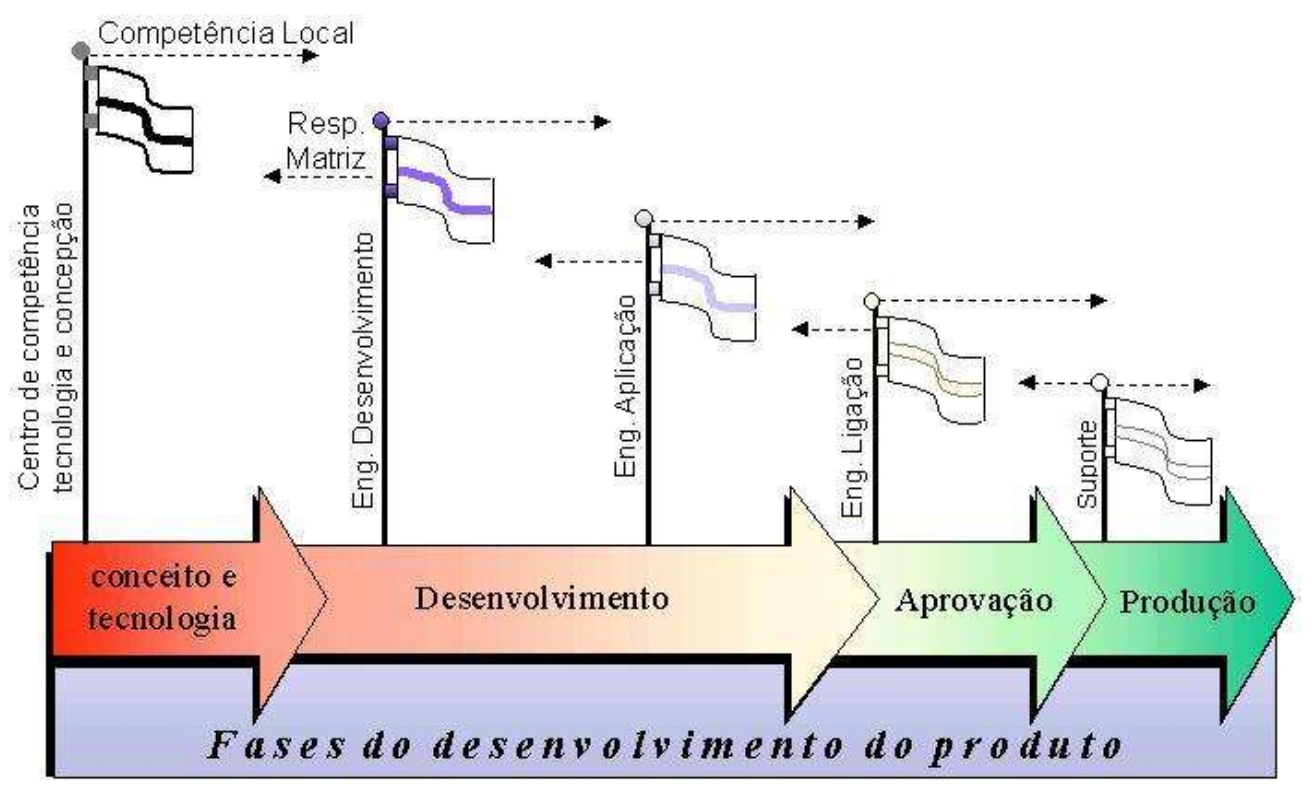

Fonte: Bagno (2007)

Em cada fase da classificação acima, percebe-se a implantação de novas estruturas pessoal e física. Toma-se como exemplo a passagem do nível de engenharia de suporte ao de engenharia de ligação. Percebe-se esta passagem pela responsabilização da subsidiária de testes sobre o produto, 
antes realizados na matriz. À execução de tais testes deve preceder a construção de uma nova estrutura física na subsidiária (pistas de testes, bancos de prova, galpões e salas, aparelhos de medição, etc.). Consequentemente nasce também uma nova estrutura organizacional na forma de designação/contratação de pessoas com perfil indicado para as novas funções, organização da estrutura hierárquica e de atribuições dos novos setores, etc.

Alves, Bomtempo e Coutinho (2005) analisam o setor petroquímico e ressaltam a importância da construção de competências organizacionais como suporte ao crescimento tecnológico das empresas brasileiras, destacando o papel da gestão do conhecimento. Neste contexto, o caminho para o desempenho de um papel mais nobre por parte destas subsidiárias estaria na maturação de sua competência de desenvolvimento de produto e na construção de competência para desenvolvimento de inovações e novas tecnologias de produto (BAGNO, 2007).

\subsection{Inovação e risco tecnológico}

Praticamente qualquer mudança não trivial em produto ou processo, desde que não haja experiência anterior, pode ser atestada como uma inovação. Assim, toda inovação envolve incerteza considerável tanto antes de sua introdução comercial quanto depois dela (NELSON \& WINTER, 1982).

Em determinados setores industriais, nos quais se verifica rápido avanço tecnológico, algumas mudanças parecem ser inevitáveis. Em muitos casos, as trajetórias obrigatórias e estratégias de avanço tecnológico estão associadas a melhorias nos componentes principais ou aspectos gerais (NELSON \& WINTER, 1982). Tais mudanças certamente podem impor novos limiares de plataformas conceituais para todos os concorrentes do mercado. O ambiente competitivo de produtos de base tecnológica, contudo, estabelece uma corrida ainda mais dinâmica. Aparentemente as vantagens das estratégias de inovação são singulares. Contudo, o fato de outras empresas buscarem rapidamente o alcance (ou mesmo superação) do patamar tecnológico imposto contribui para uma grande dinâmica de inovação.

Evitar ou não o alto risco tecnológico quando do início do desenvolvimento de um novo produto é um ponto de decisão difícil para a organização no mercado automobilístico. A opção é dada segundo um balanço entre a necessidade ou retorno esperado no mercado e o nível de incerteza por ela representado. Não raro, disponibilizar uma nova tecnologia no mercado é um desafio a ser perseguido obrigatoriamente sob pena de obsolescência acelerada, como foi o caso dos 
veículos com tecnologia bi-combustível ${ }^{2}$. Há ainda casos em que a organização opta por perder chances de sair à frente com uma nova tecnologia, mas não correr o risco a ela associado.

Consideremos o risco tecnológico como estando ligado à necessidade de aprendizado. Iniciativas que suportem a atividade de aprendizado antes da fase de desenvolvimento do produto visariam diminuir o risco associado ao desenvolvimento de determinada tecnologia ou conceito. Além disso, é condição necessária para a sobrevivência de uma inovação que a mesma seja percebida como oportunidade potencial de bons negócios (NELSON \& WINTER, 1982). Pode-se dizer que não é a qualidade científica a melhor forma de se medir uma inovação tecnológica para a companhia. É necessário, portanto, uma integração entre a atividade de pesquisa básica com a intenção organizacional.

A grande parte dos autores ligados aos estudos sobre a inovação tecnológica coloca a diferenciação de produto como elemento de grande influência na produtividade e competitividade. Adicionalmente, empresas inovadoras pagam salários substancialmente maiores do que aquelas que operam com produtos padronizados e possuem maior média de educação formal entre seus empregados (BAHIA \& ARBACHE, 2005). Paralelamente, observa-se também que a produtividade de trabalhadores de empresas inovadoras é cerca de sete vezes maior do que aquela observada em empresas de produtos padronizados (DE NIGRI, SALERNO \& CASTRO, 2005). Quanto às características do processo de busca da inovação, Koeller e Baessa (2005) identificaram nas empresas que inovam estratégias tecnológicas ofensivas, enquanto as restantes adotavam estratégia defensiva ou imitadora.

\subsection{Liderança tecnológica intermediária}

Dentro do contexto da indústria automobilística nacional, propõe-se o conceito de Liderança Tecnológica Intermediária (LTI) ao desenvolvimento evolutivo de uma subsidiária ou empresa brasileira com o objetivo de se tornar referência em características e tecnologias específicas de produto ou subsistemas dentro do mercado que explora. Em outras palavras, buscar Liderança Tecnológica Intermediária consiste em ampliar competência no desenvolvimento de produtos e criar competências de inovação tecnológica e conceitual, ao ponto de liderar uma fração determinada da gama de produtos ou seus subsistemas que respondam pelas especificidades do mercado em que se atua. Referenciando o modelo de níveis de competências discretas proposto anteriormente para a indústria automobilística, o propósito da LTI seria atingir o status de "centro de competência em tecnologia e concepção do produto". Neste contexto, propõe-se o conceito de Sistema Intra-Organizacional de Inovação (SII) ao conjunto de estratégias, iniciativas e modelos

\footnotetext{
${ }^{2}$ Possibilidade do uso de álcool ou gasolina ou sua mistura em qualquer proporção em um só veículo.
} 
que visam capacitar a organização para o alcance deste objetivo. Estes conceitos são apresentados detalhadamente em Bagno (2007).

Podemos afirmar que características da cadeia produtiva, questões legislativas, padrões, perfil social do mercado comprador, clima e outros vários fatores determinam condições de contorno que tornam o mercado local da indústria automotiva específico. Tais especificidades podem gerar pequenas alterações em projetos já definidos (como em projetos de tropicalização) ou mesmo influenciar na seleção e desenvolvimento das tecnologias que serão incorporadas ao produto. No caso brasileiro de montadoras de automóveis, demandas de consumo e particularidades do mercado local estiveram na base de investimentos em P\&D (QUADROS et al., 2000). A LTI pode também ser motivada por competição interna ao grupo industrial, no momento em que pólos de um mesmo grupo industrial disputam pelos novos negócios angariados por este grupo e, portanto, não necessariamente direcionados ao mercado local. Os arranjos propostos pelo conceito de LTI estão ilustrados na Figura 2.

Figura 2 - Modos de busca por Liderança Tecnológica Intermediária.

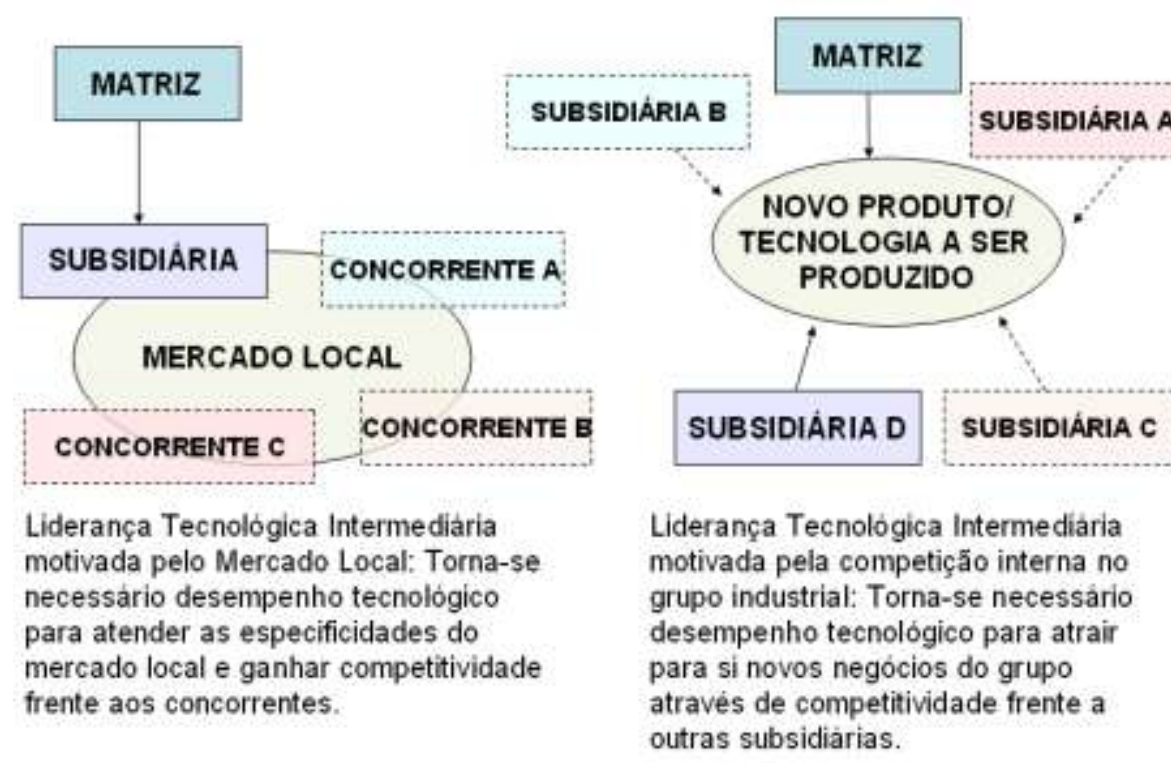

Fonte: Bagno (2007)

Há um vasto campo de estudo para entender o contexto total que envolve o enquadramento dos papéis das subsidiárias brasileiras dentro de seus grupos industriais. O conceito de LTI visa explicar de forma macroscópica o propósito empresarial motivador da construção de competências locais na indústria automobilística brasileira. Do ponto de vista da distribuição de papéis entre subsidiárias locais e matrizes assim como da maturidade das competências tecnológicas instaladas 
para que tal distribuição ocorra, o conceito aqui apresentado possui suas bases na proposta de Consoni (2004).

\section{Estratégia metodológica}

O estudo prático deste trabalho mescla características da estratégia de estudo de caso com a observação participativa, utilizando instrumentos como entrevistas não diretivas, documentos internos da organização analisada e informações provindas da imersão no ambiente de pesquisa. $\mathrm{O}$ exemplo prático sobre o qual se fundamenta o estudo de caso foi construído ao longo de 3 anos de convívio na empresa Fiat Powertrain Technologies (FPT), na subsidiária localizada em Betim-MG. Portanto, não faz parte desta abordagem, como nos estudos de caso convencionais, evitar a interferência no ambiente, que é estabelecida pela necessidade de penetração nos processos de trabalho em nível detalhado.

Com relação aos instrumentos de coleta de informações utilizados, pode-se dizer que, normalmente, este tipo de informação surge em momentos nos quais não é possível se realizar um registro instantâneo e preciso. Por esse motivo, a síntese das observações realizadas foi previamente criticada e revisada junto às principais lideranças organizacionais envolvidas no caso apresentado.

Conforme comentado por Tigre (2006), as indústrias de montagem dependem da interação humana para estabelecer as melhores formas de organização da produção. Ao contrário das indústrias de processo contínuo, as tecnologias de produto não costumam se confundir com o processo em si, havendo divisores mais claros entre estes dois campos de estudo. Tigre coloca a indústria automobilística como referência em inovação organizacional, fato este que sustenta o setor industrial escolhido para este trabalho. Quanto à escolha da organização em específico, esta se justifica por peculiaridades importantes. O primeiro ponto seria quanto ao produto: grande parte das especificidades locais de mercado enfatizadas pelo propósito empresarial da LTI, enquanto conceito focado no setor automotivo, localizam-se no perímetro dos conjuntos motopropulsores e suas respectivas aplicações. Este fato pode ser exemplificado pelo uso de combustíveis alternativos (como álcool e GNV) e incentivos fiscais ligados à cilindrada do motor. Tais exemplos tornam inegável a correlação entre caracterização local de mercado e o negócio principal da empresa escolhida para o estudo de caso. O segundo ponto é quanto a representatividade da subsidiária brasileira da Fiat (estrutura-mãe e cliente principal da FPT) tanto frente ao seu grupo industrial quanto frente ao mercado local. Em relação ao grupo Fiat, é conhecida a relevância da rentabilidade da subsidiária local e também a importância de seu centro de desenvolvimento de produtos, que é o único fora da Itália. 


\section{Estudo de caso}

\subsection{A organização}

O presente estudo de caso analisou a construção de competências organizacionais na área de desenvolvimento de produtos da subsidiária brasileira da FPT (Fiat Powertrain Technologies). A FPT é uma empresa do grupo Fiat, de origem italiana, e cujas competências organizacionais essenciais se encontram no desenvolvimento e produção de conjuntos motopropulsores (Powertrain). Estes sistemas são compostos por motor, transmissão e componentes de integração, posteriormente aplicados a veículos leves e pesados e máquinas agrícolas. Seu objetivo é prover soluções em sistemas de propulsão através de inovação e melhoramento de produtos, implementação de novos processos e pesquisa de sistemas alternativos (FPT, 2006). A subsidiária estudada está localizada em Betim-MG (Brasil).

Levando em consideração o futuro tecnológico dos motopropulsores, a atividade da FPT converge no desenvolvimento de um sistema de propulsão a células de hidrogênio, procurando identificar problemas relevantes e examinar a sua possibilidade em nível industrial. Exemplos de outras tecnologias são os novos sistemas de injeção para os motores diesel, controle eletrônico do ar nos motores com ignição a centelha, sistema eletrônico de injeção de gás natural para baixa emissão de $\mathrm{CO}_{2}$ e a tecnologia de transmissões 'robotizadas', tema do caso abordado neste estudo. As atividades de pesquisa e engenharia avançada empenham as suas três áreas de engenharia transversal: Engenharia mecânica e tecnologias de base, engenharia eletrônica e tecnologias de base e bancos de provas (FPT, 2006).

\subsection{Construção de competência organizacional para o desenvolvimento e aplicação locais de um sistema de transmissão 'robotizada'.}

Sistemas de transmissão com acionamento 'robotizado' são hoje muito utilizados nos veículos europeus, mesmo para as gamas de menores custos. O sistema de acionamento 'robotizado' realiza o processo de troca de marchas conforme modos de operação selecionados pelo usuário, através de uma tecnologia adaptada aos câmbios manuais que mescla módulos eletrônicos, eletrohidráulicos e eletromecânicos.

O primeiro veículo de uma empresa do grupo dotado deste novo sistema chegou em 2002 ao Brasil para os trabalhos de 'tropicalização'. No entanto, tais trabalhos não abrangiam modificações no sistema de transmissão, mas somente em outros subsistemas do veículo. Mesmo tendo sido lançada comercialmente na Europa, a tecnologia ainda possuía alguns inconvenientes que não 
permitiram seu inserimento em massa no mercado local. Dentre estes pode-se citar o tempo relativamente alto que o sistema necessitava para as operações de troca de marchas e outras características relacionadas às preferências do mercado brasileiro somadas ao alto custo do sistema. O comentário realizado por um engenheiro de qualidade da planta ilustra esta questão com uma abordagem focada na especificidade do mercado local:

"O sistema de transmissão 'robotizada' tinha boa aceitação na Europa mas apresentava alguns inconvenientes que prejudicavam o resultado geral de qualidade. No Brasil, o cliente não lidaria com naturalidade frente a estes inconvenientes. Aqui o veículo é um patrimônio, um bem de alto valor que deve durar muito tempo. Já na Europa esta conotação não é tão forte, as condições de uso são menos severas e o ciclo de vida dos veículos é menor."

Estes fatores, confrontados com outros produtos prioritários para o desenvolvimento local contribuíram para que não fossem, naquela época, iniciadas atividades de familiarização técnica mais aprofundada com a nova tecnologia.

A tecnologia de transmissões 'robotizadas' passou a ganhar a simpatia dos clientes na Europa e, com o lançamento de novas gerações do produto, este se convergiu paulatinamente para um sistema de menor custo e com desempenho incrementado, o que o tornaria atraente para o mercado brasileiro. Após algum tempo o fornecedor do sistema ofereceu um produto parcialmente nacionalizado para aplicação local. Esta possibilidade motivou as principais subsidiárias nacionais de montadoras de automóveis a iniciar os programas de desenvolvimento de suas aplicações. No caso da FPT, tais programas se desenvolveram sob o regime de Co-responsabilidade de projeto (Codesign) entre a empresa (conhecedora dos vínculos relacionados à aplicação do sistema sobre o produto final) e o fornecedor de primeiro nível (sistemista responsável pelo desenvolvimento interno do sistema 'robotizado'). As condições de contorno impostas pelo mercado local, associadas às competências de desenvolvimento de produto já instaladas na subsidiária brasileira determinaram que as aplicações locais da inovação proposta ocorreriam a cargo da mesma com determinado nível de suporte da matriz italiana.

Na subsidiária local da FPT, a aplicação de sistemas de transmissão com acionamento 'robotizado' envolveu o desenvolvimento de competências e estruturas organizacionais específicos. A

evidencia os principais pontos desta construção de competências.

Partindo de uma estrutura já consolidada para o desenvolvimento de transmissões mecânicas tradicionais, procurou-se suprir a carência de determinadas competências e estruturas para o time de desenvolvimento de transmissões através do compartilhamento de tais competências e recursos por 
outras equipes da área de desenvolvimento de produtos ligadas ao projeto e calibração de sistemas eletrônicos de controle do motor. Um projeto prévio de expansão física e de recursos humanos também ocorreu em antecipação à aprovação dos programas oficiais de desenvolvimento, garantindo assim uma adequação prévia da estrutura de suporte às novas atividades. Também anterior ao início do programa oficial de desenvolvimento ocorreram atividades de familiarização com a nova geração do sistema produzido para o mercado europeu. Estas atividades contaram com a importação de um veículo equipado com o sistema e um programa de treinamento técnico especializado para as equipes de engenharia de projeto e engenharia experimental. Nesta fase, engenheiros de gestão da qualidade foram enviados à matriz onde puderam estudar as falhas identificadas em campo no mercado europeu e desenhar as estratégias necessárias para prevenção de anomalias para a aplicação local.

O departamento de marketing forneceu também, antes do início efetivo do desenvolvimento do produto, um documento contendo informações importantes como:

- Objetivos do sistema na ótica do mercado;

- Avaliação técnica da concorrência, incluindo desempenho de veículos com tecnologias afins como transmissões automáticas e de variação contínua de relação da transmissão $(\mathrm{CVT})$;

- Identificação das preferências do cliente local conforme o nicho de mercado objetivado.

Tabela 1 - Preparação organizacional de uma estrutura de desenvolvimento de transmissões mecânicas para a aplicação de um sistema de transmissão 'robotizada'.

\begin{tabular}{|c|c|c|}
\hline $\begin{array}{r}\text { Compe } \\
\text { an } \\
\text { desenve }\end{array}$ & Exigênci & $\begin{array}{c}\text { Aprendizado obtido durante a } \\
\text { fase de desenvolvimento do } \\
\text { produto }\end{array}$ \\
\hline $\begin{array}{l}\text { Projeto e } \\
\text { eletrônico } \\
\text { Compe } \\
\text { senso }\end{array}$ & $\begin{array}{r}\text { Equipame } \\
\text { execução } \\
\text { subsiste }\end{array}$ & $\begin{array}{l}\text { Oportunidades de melhorias nas } \\
\text { características de } \\
\text { funcionamento do novo sistema } \\
\text { e ajustes mais detalhados do } \\
\text { projeto após resultados de testes } \\
\text { com protótipos }\end{array}$ \\
\hline $\begin{array}{r}\text { Lógica de c } \\
\text { parâmetros de } \\
\text { sistema 'rc } \\
\text { comunicação } \\
\text { contro }\end{array}$ & $\begin{array}{r}\text { de dado } \\
\text { mediç } \\
\text { atividad }\end{array}$ & $\begin{array}{r}\text { Impacto da } \\
\text { sistema 'rob } \\
\text { confiabilidad } \\
\text { dos sisten } \\
\text { transmissão }\end{array}$ \\
\hline $\begin{array}{c}\text { Avaliação e testes do } \\
\text { 'robotizado'. Formali } \\
\text { procedimentos e nor } \\
\text { trabalho. }\end{array}$ & $\begin{array}{r}\text { Redime } \\
\text { estruturas f } \\
\text { e oficin } \\
\text { ex }\end{array}$ & $\begin{array}{l}\text { Melhoria dos procedimentos de } \\
\text { projetação, calibração e } \\
\text { validação. }\end{array}$ \\
\hline
\end{tabular}




\begin{tabular}{|c|c|c|}
\hline $\begin{array}{l}\text { Princípio de funcionamento } \\
\text { geral da tecnologia, } \\
\text { características dos diferentes } \\
\text { sistemas disponíveis, principais } \\
\text { aplicações, processos de } \\
\text { produção e exigências de } \\
\text { instalação. }\end{array}$ & $\begin{array}{c}\text { Desdobramento dos impactos } \\
\text { na estrutura produtiva: nova } \\
\text { linha de montagem e } \\
\text { reavaliação do suporte logístico. }\end{array}$ & $\begin{array}{l}\text { Levantamento dos objetivos de } \\
\text { qualidade do produto para } \\
\text { produção em série. }\end{array}$ \\
\hline $\begin{array}{l}\text { Avaliação da expectativa de a } \\
\text { necessidade de novas especiali } \\
\text { trabalho para eventuais rec } \\
\text { Desdobramento destas necess }\end{array}$ & $\begin{array}{l}\text { idadento de carga de trabalho e } \\
\text { cursos humanosano de postos de } \\
\text { idades para a rede assistencial. }\end{array}$ & \\
\hline
\end{tabular}

Fonte: Adaptado de Bagno (2007).

Estes dados se convergiram então para a determinação dos modelos de automóveis sobre os quais a nova tecnologia de transmissão seria aplicada e a determinação dos parâmetros técnicos de desempenho do sistema (objetivos a serem alcançados durante o desenvolvimento do produto). Finalmente, o documento especificou então as datas-objetivo para os lançamentos dos modelos equipados com o novo opcional no mercado. Posteriormente, em fases mais avançadas do desenvolvimento, uma consultoria externa foi contratada para identificar e usuários de veículos equipados com tecnologias concorrentes e clientes dos modelos que viriam a receber o novo opcional. Estas pessoas foram então convidadas a dirigir veículos prototipais equipados com a transmissão 'robotizada', emitindo em seguida seu parecer. Além de guiar as fases finais de ajuste do produto em desenvolvimento, tais informações foram determinantes para a elaboração das estratégias de marketing, evidenciando os pontos fortes do produto e de maior atenção do cliente a serem explorados nas campanhas comerciais.

Pode ser observado um grande envolvimento na equipe de pessoas ligadas ao processo produtivo e em maior número do que em projetos de tecnologia conhecida. Conforme ilustrado na Figura 3, o impacto da nova tecnologia nos meios de produção era claro e viria certamente a se desdobrar também novos processos de trabalho e organização física na linha de produção. Cabe também destacar o papel diferenciado que as equipes de desenvolvimento do produto tiveram na elaboração dos treinamentos relativos ao novo sistema. Em primeira instância tais treinamentos objetivaram a capacitação das próprias pessoas envolvidas no processo de desenvolvimento das primeiras aplicações, profissionais responsáveis pela adaptação das linhas de produção e aqueles inseridos em atividades de gestão e controle. Em um segundo momento este esforço se convergiu para a construção da estratégia de treinamento e documentação serem aplicados sobre as equipes de assistência técnica. O desdobramento estratégico da inovação na etapa de suporte ao cliente culminou com o desenvolvimento de uma equipe de especialistas técnicos responsáveis por acompanhar o comportamento do produto em campo (principalmente no período de inserção no 
mercado) e na criação de uma central de atendimento telefônico 24 horas com o objetivo de esclarecer dúvidas no uso e manutenção do sistema.

A reduzida experiência anterior com projetos afins tanto da parte da equipe interna de desenvolvimento quanto da parte do fornecedor local do sistema, ocasionou ainda um período de aprendizado intenso em paralelo com o desenvolvimento do produto. Tal aprendizado teve como consequiência um grande número de ações de melhoria nesta etapa, consumindo maior quantidade de recursos se comparado a um projeto padrão. Porém, dentro de uma margem de variação gerenciável de tempo, custo e qualidade o projeto pôde ser desenvolvido e validado dentro de um prazo próximo ao de um programa padrão (de tecnologia conhecida) e atendendo aos critérios de qualidade do produto final ${ }^{3}$. Cabe ainda ressaltar o esforço desprendido na contínua reavaliação de parâmetros de validação do produto, principalmente em quesitos especiais para o mercado local como infiltração de água e poeira, escalonamento de marchas e durabilidade dos componentes da embreagem.

Figura 3 - Novas tecnologias de produto e impacto nas áreas produtivas

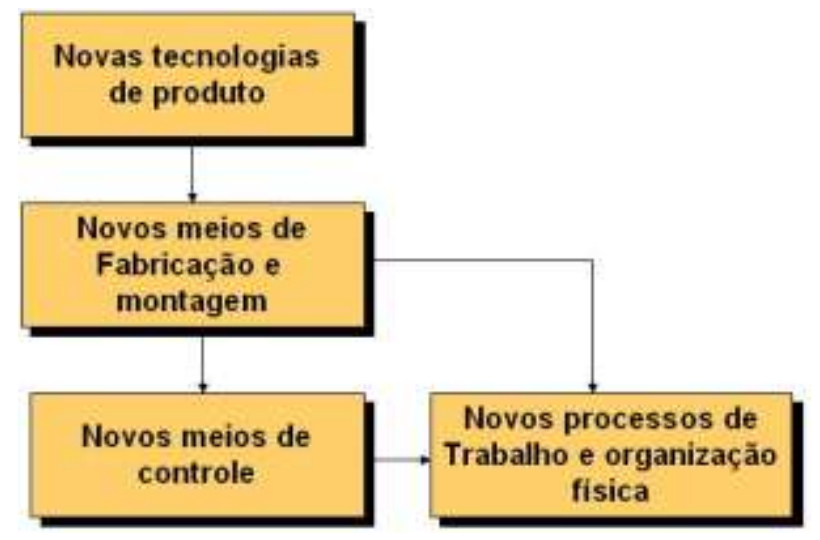

\section{Ainda na}

, as novas competências e conhecimentos individuais necessários dizem respeito a atividades de aprendizagem e formação de competências que devem ocorrer antes do início do programa de desenvolvimento de produto. Podemos identificar então existem dois tipos distintos de atividades:

- Atividades de exploração e pesquisa técnica atribuível a grupos de engenharia avançada;

- Atividades relacionadas à consolidação de novas competências, compreendendo:

- Preparação e organização de estrutura física (equipamentos, bancos de prova, galpões, recursos de informática, etc);

- Seleção e desenvolvimento de recursos humanos;

\footnotetext{
${ }^{3}$ Uma das dificuldades adicionais para a gestão do processo de desenvolvimento foi a aplicação do sistema robotizado simultaneamente em várias plataformas de produtos (veículos), antes que uma primeira aplicação pudesse ser consolidada.
} 
- Redesign organizacional (estrutura de comunicação, funções e autoridades);

- Processos organizacionais e normas;

- Atividades de planejamento de portfólio com provisão de recursos para os programas oficiais de desenvolvimento do produto coerente com o risco técnico associado à inovação ${ }^{4}$;

- Outros.

A consolidação das novas competências necessárias inicia-se antes do início efetivo do processo de desenvolvimento do produto comercial, prolonga-se durante o processo (questionando e amadurecendo os métodos aplicados) e após o mesmo (promovendo a multiplicação do aprendizado ocorrido no projeto piloto). Rapidamente podemos perceber que o aprendizado e construção de competências relacionados na primeira coluna podem ter conseqüências negativas se ocorrem dentro das etapas determinadas do desenvolvimento do produto comercial. Em outras palavras, se a construção prévia de competências não ocorre diante da necessidade da inovação, a organização pode viver sérios riscos dentro de um programa de desenvolvimento de produto.

É natural que a pouca familiaridade e experiência de desenvolvimento com a nova tecnologia ocasione em um aprendizado intenso também após a construção prévia de competências, já durante o desenvolvimento do produto. Tal aprendizado vem, contudo, lapidar uma competência previamente planejada e construída e não deve ser confundido com o tipo de aprendizado que ocorre na fase precedente. Acredita-se que seria possível um maior acúmulo de conhecimento e experiência se as atividades exploração técnica da nova tecnologia estivessem sendo realizadas desde sua primeira geração, representada pelo veículo disponível para tropicalização poucos anos antes. O contato com as equipes da matriz e seus fornecedores de sistema poderia ter certamente acelerado e antecipado parte do processo de aprendizado.

Alguns conhecimentos relacionados às especificidades do mercado e localizados no departamento de marketing tiveram relevante importância como o conhecimento das preferências do cliente brasileiro quanto às operações automáticas de troca de marchas. Este e outros parâmetros mais detalhados serão exigências primárias da especificação técnica do produto, procurando garantir o sucesso do produto final.

Em síntese, através do caso apresentado são identificados pontos fundamentais para a construção de competências como a necessidade de implementação de mecanismos de aprendizado organizacional, desenvolvimento de pesquisa básica e estabelecimento prévio de estruturas pessoal e física que suportem o processo de inovação. Uma vez que tais estruturas podem variar fortemente conforme o tipo de inovação a ser desenvolvida, destaca-se a importância da habilidade de contínuo

\footnotetext{
${ }^{4}$ Não foi identificada uma regra básica para tal planejamento, mas pôde ser verificado o reconhecimento de um nível de incerteza maior refletido na previsão de retrabalhos, números de protótipos e verbas para modificações.
} 
questionamento e recriação da estrutura organizacional. Em outras palavras, é necessário um levantamento recorrente de necessidades no modelo representado pela

para suportar uma estratégia organizacional que privilegie a inovação tecnológica local.

Finalmente, é importante frisar através do caso utilizado que a estruturação e o investimento que ocorreram antes do desenvolvimento da aplicação comercial do produto devem ser regidos por um rigoroso planejamento de mercado. Tal planejamento envolve a análise da real necessidade da nova tecnologia (valor agregado no mercado local), ao contrário do que ocorre na atividade de exploração tecnológica. Esta última deve acompanhar as tendências tecnológicas mesmo que não haja nenhuma previsão de lançamentos comerciais. Diversas outras tendências tecnológicas foram cogitadas anteriormente para os sistemas de transmissão sem que se tornassem sucessos comerciais no mercado local. Como um exemplo mais conhecido, vale citar a transmissão automática tradicional que se tornou um padrão no mercado americano. Tal tecnologia, quando das suas primeiras aplicações, certamente haveria de ser explorada por um grupo de engenharia avançada. Todavia, se a organização tivesse investido prematuramente em pesadas estruturas para suportar um possível desenvolvimento nacional, certamente teria cometido um erro, pois tal não apresenta o mesmo nível de aceitação no mercado brasileiro. No caso dos sistemas de transmissão 'robotizada', a organização selecionou tecnologia que seria de fato aplicada ao produto local e construiu a competência necessária para este desenvolvimento antes do início do programa oficial de desenvolvimento da aplicação comercial.

\section{Conclusão}

O desenvolvimento de novos conceitos de produtos e tecnologias envolve necessariamente a construção de novo conhecimento e competências em âmbito organizacional. Promover tal mudança, contudo, envolve muitos aspectos de naturezas distintas como mecanismos formais de motivação ao aprendizado, direcionamento estratégico, ambiente de trabalho e cultura, relacionamento com o mercado, relacionamento entre empresas do grupo, empresas da cadeia produtiva e com outras organizações, formação de capital humano, dentre vários outros. Isto traduz os esforços específicos para obtenção, assimilação, adaptação, melhoria e criação de tecnologia. A abordagem por competências vem aqui agregar uma perspectiva fundamental: é necessário uma estrutura organizacional apropriada para que os processos de aprendizado se desenvolvam corretamente e agreguem valor de forma efetiva na organização. Torna-se fundamental às organizações inseridas no propósito da Liderança Tecnológica Intermediária entender o processo total de inovação como essencialmente mais abrangente do que o desenvolvimento de novos produtos e não limitado ao incentivo às atividades de pesquisa. Este reconhecimento deve levar ao 
contínuo questionamento e redesenho das estruturas e ferramentas organizacionais visando suportar a estratégia local de inovação tecnológica.

As verificações acerca das competências operacionais historicamente privilegiadas na indústria automobilística brasileira e a necessidade de mudança deste quadro reforçam os objetivos propostos na raiz deste trabalho. Como pôde ser constatado, a construção de competências tecnológicas pode significar a sobrevivência de médio e longo prazo da economia local neste setor. No caso das subsidiárias dos grupos globais localizadas em países periféricos, a atração das atividades de desenvolvimento de produtos e tecnologias vêm agregar novas dimensões ao papel exercido por estas organizações. Tais dimensões vêm tanto reposicionar países como o Brasil dentro do percurso do desenvolvimento tecnológico quanto agregar funções mais nobres e mais valorizadas no quadro de profissionais exigidos por estas organizações em suas subsidiárias locais. No caso de cadeias produtivas extensas como a da indústria automobilística, espera-se, no médio prazo, que tal desenvolvimento de competências abranja também outras empresas, em maior ou menor grau, conforme sua inserção no contexto da LTI.

\section{Referências}

AEA - Associação de Engenharia Automotiva. Meio Século da Indústria Automobilística Brasileira. In: SIMPÓSIO INTERNACIONAL DE ENGENHARIA AUTOMOTIVA, 13, São Paulo, 2005. Anais do XVIII Simpósio Internacional de Engenharia Automotiva. São Paulo: AEA, 2005.

ALVES, F.; BOMTEMPO, J.; COUTINHO, P. Competências para inovar na indústria petroquímica brasileira. Revista Brasileira de Inovação, v.4, n.2, Jul./Dez. 2005.

BAGNO, R. B. Liderança Tecnológica Intermediária e Sistema Intra-organizacional de Inovação: Construindo novas competências tecnológicas em uma subsidiária brasileira da indústria automobilística. Belo Horizonte, 2007. Dissertação (mestrado em Engenharia de Produção) - Escola de Engenharia, Universidade Federal de Minas Gerais.

BAHIA, L. D.; ARBACHE, J. S. Diferenciação salarial segundo critérios de desempenho das firmas industriais brasileiras. In: SALERNO, M. S.; DE NIGRI, J. A. (Orgs.) Inovação, padrões tecnológicos e desempenho das firmas industriais brasileiras. Brasília: IPEA, 2005.

CONSONI, F. L. Da Tropicalização ao Projeto de Veículos: um estudo das competências em desenvolvimento de produtos nas montadoras de automóveis no Brasil. Campinas, 2004. 267f. Tese (doutorado em Política Científica e Tecnológica) - Instituto de Geociências, UNICAMP.

DE NIGRI, J. A.; SALERNO, M. S.; CASTRO, A. B. Inovações, padrões tecnológicos e desempenho das firmas industriais brasileiras. In: SALERNO, M. S.; DE NIGRI, J. A. (Orgs.) Inovação, padrões tecnológicos e desempenho das firmas industriais brasileiras. Brasília: IPEA, 2005.

DIAS, A. V. C. Produto Mundial, Engenharia Brasileira: integração de subsidiárias no desenvolvimento de produtos globais na indústria automobilística. São Paulo, 2003. Tese (doutorado em Engenharia) - Escola Politécnica, USP.

FIGUEIREDO, P. N. Aprendizagem Tecnológica e Performance Competitiva. Rio de Janeiro: Editora FGV, 292 p. 2003.

Aprendizagem Tecnológica e Inovação Industrial em Economias Emergentes: uma breve Contribuição para o Desenho e Implementação de Estudos Empíricos e Estratégias no Brasil. Revista Brasileira de Inovação, v.3, n.2. p.323-361. 2004. 
FLEURY, A. Gerenciamento do Desenvolvimento de Produtos na Economia Globalizada. In: CONGRESSO BRASILEIRO DE GESTÃO DE DESENVOLVIMENTO DE PRODUTO, 1, Belo Horizonte, 1999. Anais do 10. Congresso Brasileiro de Gestão de Desenvolvimento do Produto. Belo Horizonte: Universidade Federal de Minas Gerais, 1999. p. 1-10.

FLEURY, A.; FLEURY, M. T. L.. Aprendizagem e inovação organizacional: as experiências de Japão, Coréia e Brasil. 2. ed. São Paulo: Atlas, 1997. 237p.

Estratégias empresariais e formação de competências: um quebra-cabeça caleidoscópico da indústria brasileira. São Paulo: Atlas, 2000. 160p.

FPT - Powertrain Technologies. Criatividade como propulsão. Release Institucional. 2006.

GALINA, S. V. R. Desenvolvimento global de produtos: o papel das subsidiárias brasileiras de fornecedores de equipamentos do setor de telecomunicações. São Paulo, 2003. 318f. Tese (doutorado em Engenharia) - Escola Politécnica, USP.

KOELLER, P.; BAESSA, A. R. Inovação tecnológica na indústria brasileira. In: SALERNO, M. S.; DE NIGRI, J. A. (Orgs.) Inovação, padrões tecnológicos e desempenho das firmas industriais brasileiras. Brasília: IPEA, 2005.

NELSON, R. R.; WINTER, S. G. In search of a useful theory of innovation. Research Policy, v.6, n.1, p.36-77, 1977. In: Revista Brasileira de Inovação, v.3, n.2. p.243-282. 2004.

An Evolutionary theory of economic change. Cambridge, Mass; London: The Belknap Press of Harvard University Press, 1982.

QUADROS, C. R.; et al. Globalização e capacitação tecnológica na cadeia produtiva da indústria automobilística: qual é o papel do Mercosul? Campinas: GEMPI/DPCT/IG/UNICAMP, 2000.

TIGRE, P. B. Gestão da Inovação: A economia da tecnologia no Brasil. Rio de Janeiro: Elsevier, 2006.

\begin{abstract}
The aim of this article is to describe how a Brazilian Automotive Subsidiary has been building up its technological competences on innovating products, under a concept named as 'Intermediate Technological Leadership' (ITL). After a historical review of the technological evolution of automotive industry in Brazil, a brief literature analysis establishes a direct relationship between the role played by Brazilian subsidiaries of global organizations and the search of management and technological knowledge, associated with organizational structure, necessary for the full achievement of ITL. The discussion is illustrated by the analysis of competence construction applied to the development of a robotized system of car transmission. This analysis was carried out through: immersion within the organization, data collection based on internal documents and nondirective interviews with leaders and engineers directly involved in the process. The case study revealed some fundamental themes for the competence building, such as the need for creating mechanisms of organizational learning, development of technological research, and construction of physical and organizational structure. Amongst the main benefits of this proactive stance of local subsidiaries in the construction of these new competences, it stands out the development of firms involved in the productive chain and the increase of qualified jobs created in the sector.
\end{abstract}

Key-words: Technological competence, product development, technological innovation, automotive industry. 


\section{Dados dos autores:}

Nome completo: Raoni Barros Bagno

Filiação institucional: Fiat Powertrain Technologies

Departamento: Desenvolvimento do Produto

Função ou cargo ocupado: Engenheiro de Projeto

Endereço completo para correspondência (bairro, cidade, estado, país e CEP): Rua Ophil Ribeiro 265, Apto 212, Bairro Palmeiras, Belo Horizonte, MG, Brasil, CEP 30580-020

Telefones para contato: :+55-31-3321-2759; +55-31-9162-5488

e-mail: rbagno@uai.com.br

Nome completo: Lin Chih Cheng

Filiação institucional: Universidade Federal de Minas Gerais - Escola de Engenharia

Departamento: Engenharia de Produção

Função ou cargo ocupado: Professor Associado

Endereço completo para correspondência: Av. Antônio Carlos, 6627. Pampulha, Belo Horizonte, MG, Brasil. CEP 31270-000

Telefones para contato: $+55-31-3409-4903$

e-mail: lincheng@dep.ufmg.br

Recebido para publicação em: 01/02 /2008

Aceito para publicação em: 29/02/2008 